\title{
INTERDIÇÃO DE GÊNERO: A LEI QUE SILENCIA O CORPO
}

\author{
INTERDICTION DE GENRE: LA LOI QUI FAIT TAIRE LE CORP
}

${ }^{1}$ Renato Duro Dias

\section{RESUMO}

Esta investigação discute as identidades de gênero com base na análise da obra La ley no escrita (2012) de Oihana Cordero. O trabalho da artista visual tem como objetivo provocar reflexão sobre as leis e normas jurídico-sociais que existem em torno do caráter ficcional e performativo de gênero, desvelando novas leituras sobre a escritura do corpo. Trata-se de uma obra escultórica (KRAUSS, 1984) composta por uma base branca, uma espada e conjunto de folhas em que se expressam, por meio de um contrato de gênero, como se articulam, interseccionam e se impõe interdições às possibilidades de gênero. Assim, evidenciam-se regras e regulamentações impostas pelo binarismo de gênero que violentam sujeitos e aprisionam identidades em prol da normalização (normatização) dos corpos. Para esta investigação problematizam-se os conceitos de gênero, corpo assujeitado, normatividade e performance em Butler (2012a, 2012b, 2013), Foucault (1997, 1998, 2014). Fraser (2002,

2006, 2009), Scott (2008), Cordero (2012) e Preciado (2011). Cordero (2012), em sua obra, nos apresenta múltiplas cópias de um contrato impresso transpassadas por uma espada. Tratase de uma metáfora, uma forma de representação dogmatizada do corpo através de escrituras visíveis e invisíveis que compõe e naturalizam as identidades de gênero em uma dualidade obscurantista homem/mulher. Esta obra como objeto conceitual (FREIRE, 2006) produz uma (im)potência expressa para além de um documento legal perfurado, ela objetiva provocar as pessoas a refletir sobre suas práticas e seus corpos, mas, sobretudo, reflexionar como estes perímetros são de difícil transgressão. Ao se analisar a possível intersecção sobre as identidades de gênero e um objeto artístico dentro do campo jurídico espera-se manejar elementos capazes de desvelar as tecnologias políticas corporais complexas (LAURENTIS, 1989) e assim direcionar luz as multifacetadas matrizes de produção dos sujeitos.

Palavras-chave: Arte, Direito, Gênero, Corpos, Sujeitos

\footnotetext{
${ }^{1}$ Doutor em Educação pela Universidade Federal de Pelotas - UFPEL, Rio Grande do Sul (Brasil). Professor do Curso de Mestrado em Direito pela Universidade Federal do Rio Grande - FURG, Rio Grande do Sul (Brasil).

E-mail: renatodurodias@gmail.com
} 


\section{RÉSUMÉ}

Cette recherche discute les identités de genre avec la base dans l'analyse du travail La Ley no escrita (2012) d'Oihana Cordero. Le travail de l'artiste plasticien a comme l'objectif provoque la réflexion sur les lois et les normes juridiques-sociales qu'ils existent autour du caractère ficcional et le genre performatife, révélant de nouvelles lectures sur l'acte du corps. C'est un travail sculptural (KRAUSS, 1984), composé par une base blanche, une épée et un groupe de feuilles, dans lesquelles ils sont exprimés, par un contrat de genre, comme ils se prononcent, interseccionam et c'est des interdictions imposées aux possibilités de genre. Comme ceci, les règles et des règlements sont faits la preuve imposés par le binarisme du genre que la force soumet et ils arrêtent des identités pour le compte de la normalisation (normatisation) des corps. Pour cette enquête les concepts de genre sont problematize, le corps subjugué, la normativité et de la performance dans le Butler (2012a, 2012b, 2013), Foucault (1997, 1998, 2014), Fraser (2002, 2006, 2009), Scott (2008), Cordero (2012) et Preciado (2011). Cordero (2012), dans son travail, nous présente les copies multiples d'un contrat de papier imprimé a passé par une épée. C'est une métaphore, une forme de représentation dogmatizé du corps par les actes visibles et invisibles qui compose et ils naturalisent les identités de genre dans une dualité obscurantiste homme/femme. Ce travail comme l'objet conceptuel (FREIRE 2006) produit la puissance exprimée pour en plus d'un document légal perforé, elle vise à provoquer les gens de contempler sur leurs pratiques et leurs corps, mais, par-dessus tout, réfléchir comme ces périmètres ont de transgression difficile. Lors de l'analyse de l'intersection possible des identités de genre et un objet artistique dans le domaine juridique est prévu pour gérer des éléments capables de révéler les technologies complexes corporels politiques (LAURENTIS, 1989) et comme ceci pour aborder la multiforme production des sujets.

Mots-clés: Art, Droit, Genre, Corps, Sujet 


\title{
Introdução
}

Este estudo pretende discutir as identidades de gênero com base na análise da obra La ley no escrita (CORDERO, 2012). O trabalho da artista visual tem como objetivo provocar a reflexão pública sobre as leis e normas sociais que existem em torno do caráter ficcional e performativo de gênero.

De acordo com Preciado (2011),

\begin{abstract}
el sistema de sexo-género es un sistema de escritura. El cuerpo es un texto socialmente construido, un archivo orgánico de la historia de la humanidad como historia de la producción-reproducción sexual, en la que ciertos códigos se naturalizan, otros quedan elípticos y otros son sistemáticamente eliminados o tachados. (2011, p. 18)
\end{abstract}

Em sua obra, Cordero (2012) nos propõe interrogar sobre o sistema sexo-gênero sob o ponto de vista da arte contemporânea, o que não nos resulta tarefa fácil, já que para a maioria das pessoas, uma obra de arte se traduz em uma pintura, um desenho ou uma escultura cujas características se expressam e são representadas na estética do belo e pelo caráter da genialidade artística.

O aparente caráter simbólico de um contrato sobre o tema de gênero, apresentado pela obra em forma de 800 folhas textualmente repetidas, nos dá a dimensão pós-moderna que a artista se lança: entrelaçar produção visual e estudos de gênero para (des)construir o ensurdecedor silêncio provocado pelas múltiplas interdições que o sistema sexo-gênero nos impõem em diferentes dispositivos sociais e psíquicos.

Pretende-se, tendo em conta os estudos sobre iconografia e iconologia de Panofsky (1986), contextualizar estes discursos e representações de gênero expressos em La Ley no escrita (2012), já que de acordo com Panofsky,

\footnotetext{
ao concebermos assim as formas puras, os motivos, imagens, estórias e alegorias, como manifestações de princípios básicos e gerais, interpretamos todos esses elementos como sendo o que Ernst Cassirer chamou de valores "simbólicos". (1986, p. 53)
}

Nesta busca por significações, através do que a obra autoral nos revela, instaura-se um processo de

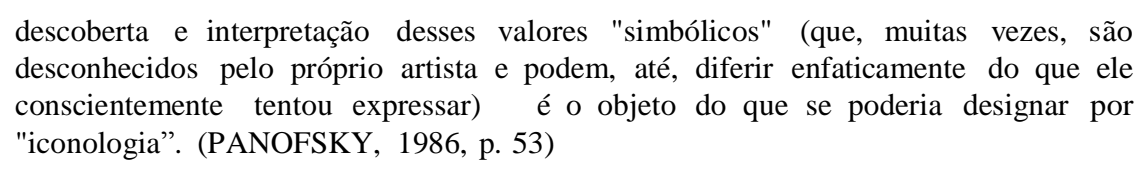
desconhecidos pelo próprio artista e podem, até, diferir enfaticamente do que ele conscientemente tentou expressar) é o objeto do que se poderia designar por "iconologia”. (PANOFSKY, 1986, p. 53) 
Entre folhas de papel, uma base e uma espada, espacializados em um "cubo branco", reverberam-se múltiplos mecanismos (imagens) de opressão e de dominação cuja centralidade discursiva opera sobre as tecnologias de/do gênero (LAURENTIS, 1989). Neste ponto e para esta investigação, problematizar-se-ão os conceitos de gênero, corpos, norma e performatividade em Butler (2012a, 2012b e 2013), Laurentis (1989) Fraser (2002, 2006, 2009), Scott (2008), Preciado (2011) e Lamas (2002, 2013) e, ainda Foucault (1997, 1998, 2014) e Bourdieu (1998, 2012).

La ley no escrita (2012), objeto de arte composto de múltiplas cópias de um contrato de gênero impressos e transpassados por uma espada, reivindica uma desnaturalização da subordinação feminina. Trata de metaforizar uma forma de representação dogmatizada do corpo através de escrituras visíveis e invisíveis que compõe e naturalizam as identidades de gênero em uma dualidade obscurantista homem/mulher.

La ley no escrita (2012) interroga-nos sobre as formas de poder hegemônico, potencializa múltiplas escrituras, em corpos múltiplos, transgride a lei, jurídica e socialmente, porque "la arquitectura corporal es política". (PRECIADO, 2011, p. 23).

1. La ley no escrita ${ }^{1}$

Trata-se de uma obra escultórica (KRAUSS, 1984) composta por uma base branca, uma espada e conjunto de folhas em que se expressam, por meio de um contrato de gênero, como se articulam, interseccionam e se impõe interdições às possibilidades de gênero.

Segundo a própria $\operatorname{artista}^{2}$ (2015), La ley no escrita (2012) surge como uma necessidade de escrever, produzir e mostrar conclusões ou ideias a partir de análises e discussões em um grupo de ativismo feminista de Granada, Espanha. Uma obra cuja apresentação interpela os sujeitos a transpor as estruturas cognitivas inscritas nos corpos e nas mentes, enraizadas durante muitos anos através de paradigmáticas violências simbólicas (BOURDIEU, 1998, 2011).

\footnotetext{
${ }^{1}$ Escultura de Oihana Cordero (2012).

${ }^{2}$ Entrevista com Oihana Cordero. http://curadormag.com/hola-oihana/ <acesso em 10.03.2015>
} 


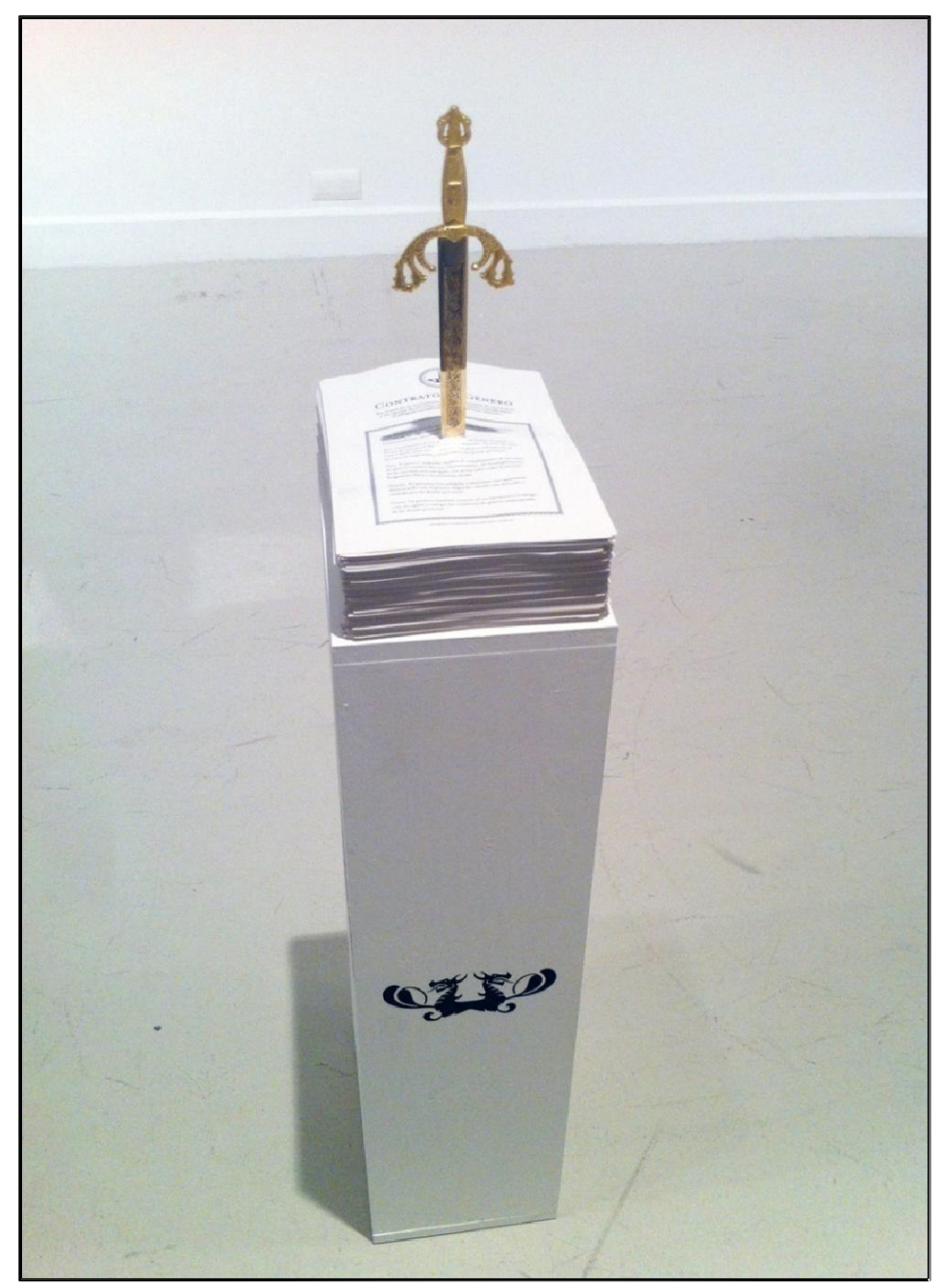

La ley no escrita, Cordero (2012). A obra.

Fonte: www.oihana.cordero.com 
A proposta da obra La ley no escrita (2012) começa a partir de um diálogo da artista com um parceiro de grupo, José Miguel Pérez Marcos. Em determinado momento, Pérez Marcos (2012) diz ${ }^{3}$ a Cordero: "O novo São Jorge tem cara de Estado, e a lança que mata tem forma de lei ${ }^{4}$ ", referindo-se ao mito do dragão e de São Jorge.

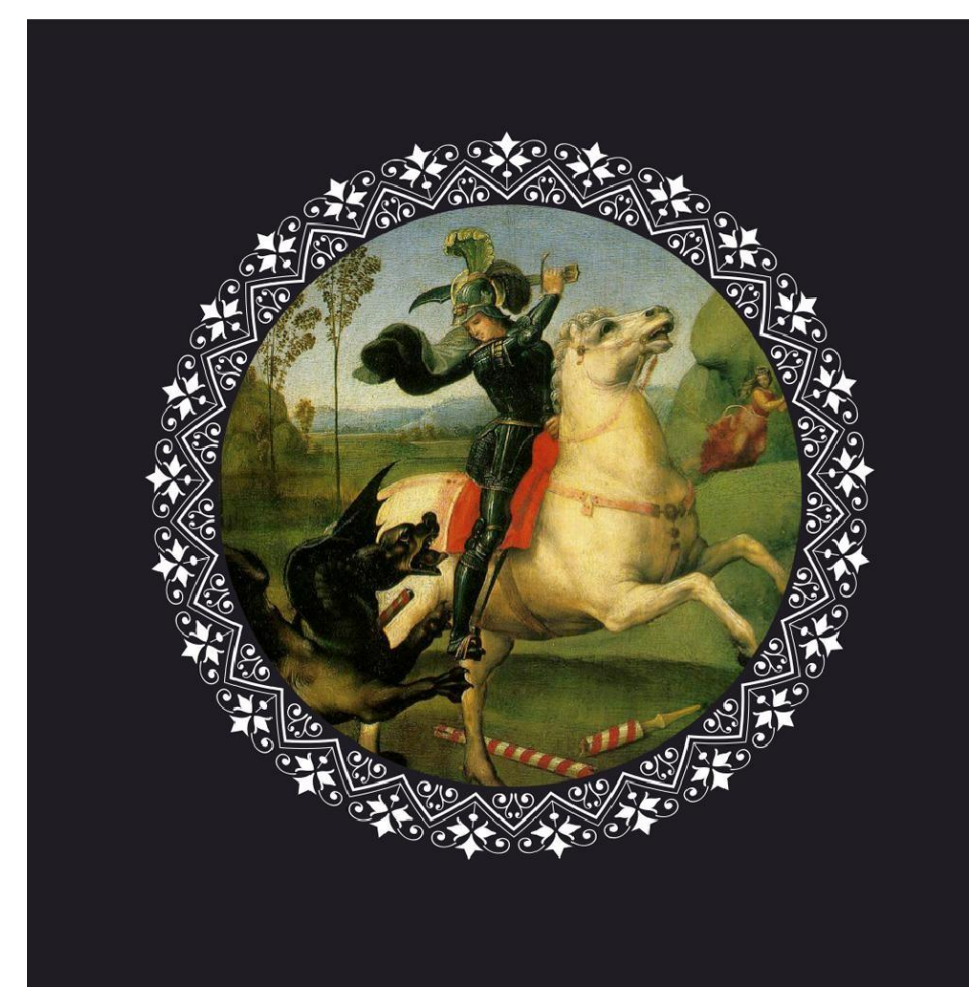

Fonte: Adaptação ${ }^{5}$ de Oihana Cordero (2012) da obra "São Jorge e o Dragão" de Raphael Sanzio ${ }^{6}$ (1506).

Segundo a artista visual, a obra aprofunda-se em analisar as potências expressas nestas leis invisíveis, que, porque muitas vezes, pesam mais do que as leis escritas.

Para mim estava muito claro por onde começar. Pretendia mostrar um contrato que assinamos antes mesmo do nascimento e, mais, cumprimos ao longo de nossas vidas, sem exceção: o contrato de sexo-gênero. Ele (contrato) irá revelar fatos e conceitos que moldam nossas vidas, regras e leis que nos regem. Algumas de nossas leis podem ser ignoradas sem consequências graves, porém, a transgressão dos outros pode envolver punições vitais e acarretar uma forte exclusão social. (CORDERO, 2015)

\footnotetext{
3 www.oihana.cordero.com

4 Tradução livre de "El nuevo San Jorge tiene cara de estado, y la lanza que mata tiene forma de ley." PÉREZ MARCOS, José Miguel: "Dragón metálico: Texto justificativo de la obra expuesta". Introducción al Proyecto Escultórico. Granada: Universidad de Bellas Artes Alonso Cano de Granada, 2012

${ }_{6}^{5}$ www.oihana.cordero.com

6 www.nga.gov
} 


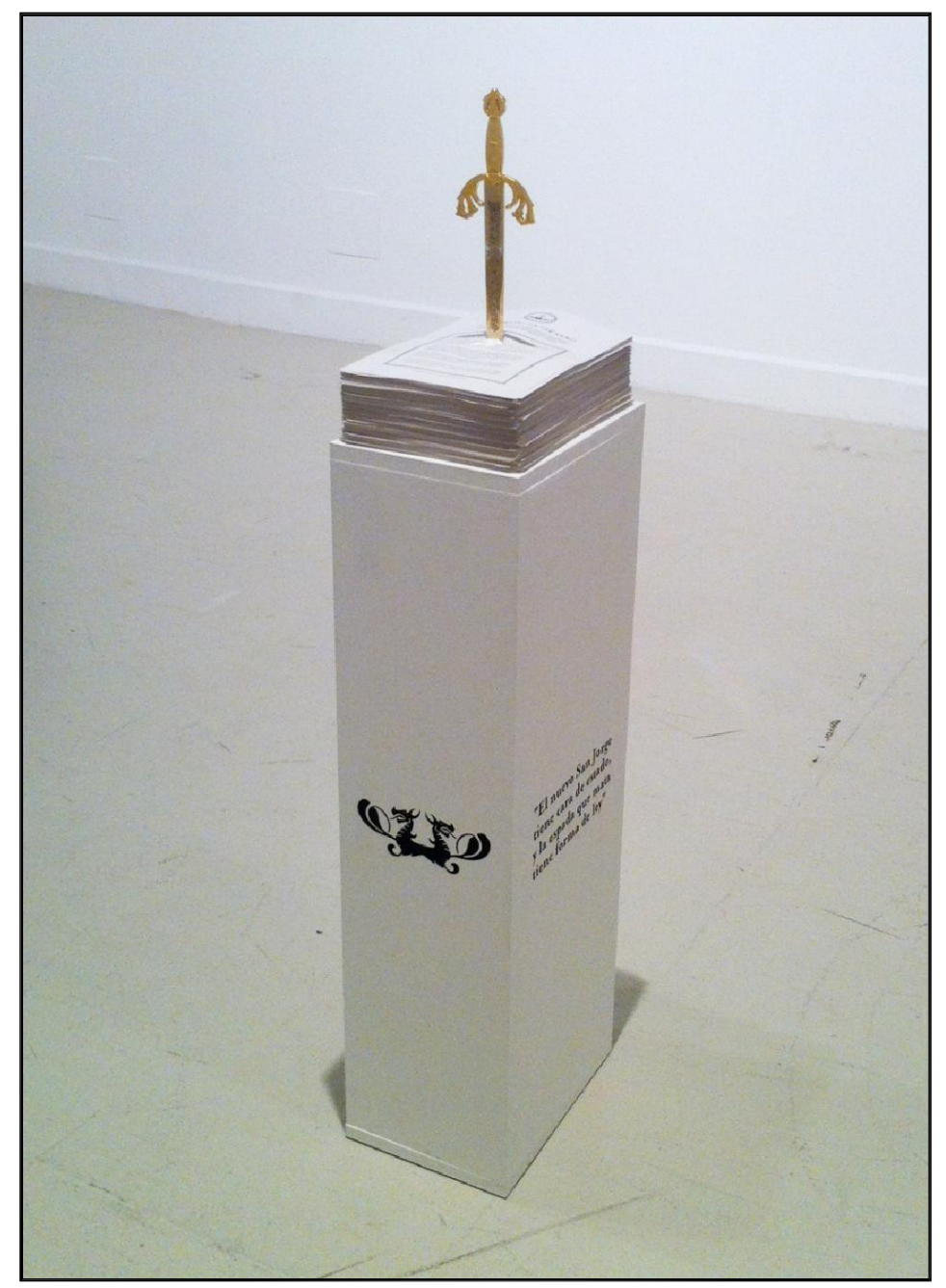

La ley no escrita, Cordero (2012). A obra sob outro ângulo.

Fonte: www.oihana.cordero.com 


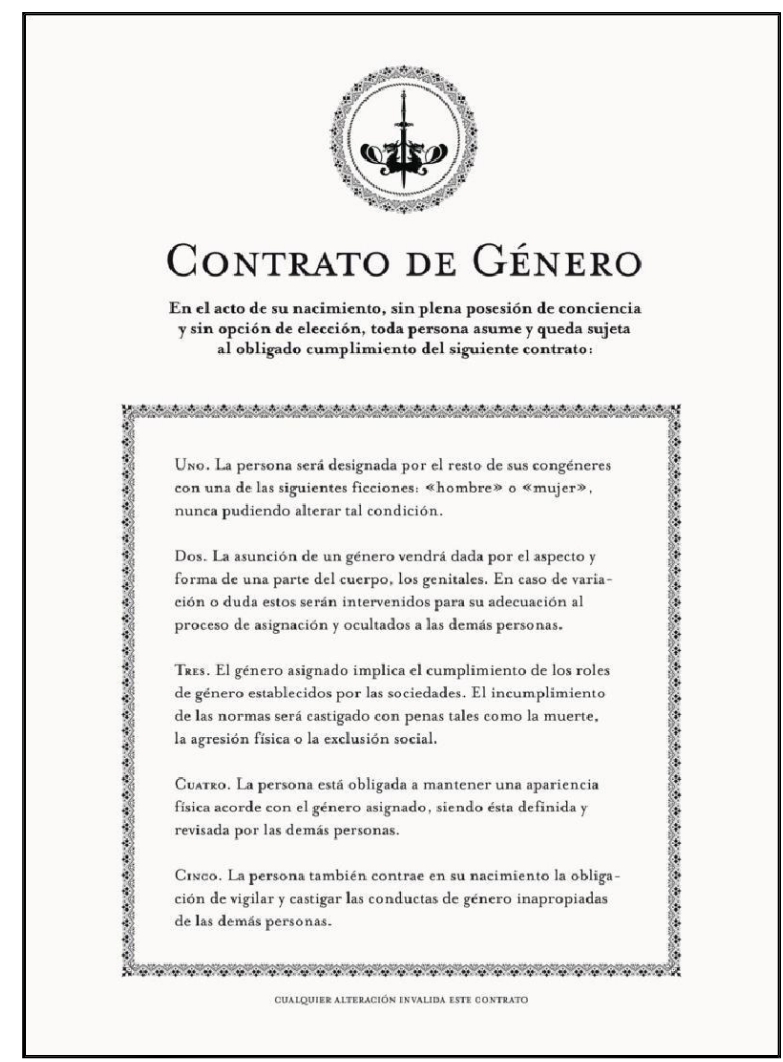

La ley no escrita, Cordero (2012). O contrato de género. Fonte: www.oihana.cordero.com 
A metáfora contratual explicitada por Cordero (2012) estabelece uma direta relação entre a atribuição de identidade de gênero ao nascimento do sujeito, impondo-lhe um nome e uma marca indelével, capaz de produzir sentido a todo e qualquer corpo. Esta assujeitação produz abjeção a qualquer organismo corporal que não se inscreva dentro da heteronormativização binarizante.

Nestes espectros de corpos rígidos e inflexíveis da construção social identitária, produz-se uma insensata exclusão social. Encontram-se aí corpos trans, híbridos, plurais e identidades de gênero não compartimentadas nas caixas pré-estabelecidas para o que é tradicionalmente ${ }^{7}$ construído (constituído e naturalizado) como corpo masculino e feminino.

A imutabilidade deste constructo identitário é um dos indiciários que se insere no discurso médico (FOUCAULT, 2014): “é um menino”, “é uma menina”. A produção de significações que se traduz a partir deste discurso faz gerar uma inevitável e desastrosa sequência de novos discursos e práticas que acabam enjaulando/aprisionando o corpo a uma única e admissível performatividade (BUTLER, 2013).

Deste discurso derivam múltiplas práticas de controle social sobre este corpo.

\begin{abstract}
Nada há de exclusivamente "natural" nesse terreno, a começar pela própria concepção de corpo, ou mesmo de natureza. Através de processos culturais, definimos o que é - ou não - natural; produzimos e transformamos a natureza e a biologia e, conseqüentemente, as tornamos históricas. Os corpos ganham sentido socialmente. A inscrição dos gêneros - feminino ou masculino - nos corpos é feita, sempre, no contextode uma determinada cultura e, portanto, com as marcas dessa cultura. As possibilidades da sexualidade das formas de expressar os desejos e prazeres - também são sempre socialmente estabelecidas e codificadas. As identidades de gênero e sexuais são, portanto, compostas e definidas por relações sociais, elas são moldadas pelas redes de poder de uma sociedade. (LOURO, 2000, p.10)
\end{abstract}

Foucault (2014), em A ordem do discurso, adverte para as interdições discursivas que nos impedem de falar de tudo em qualquer circunstância e que, portanto, geram um ritual de negação.

\footnotetext{
Notaria apenas que, em nossos dias, as regiões onde a grade é mais cercada, onde os buracos negros se multiplicam, são as regiões da sexualidade e as da política: como se o discurso, longe de ser esse elemento transparente ou neutro no qual a sexualidade se desarma e a política pacífica, fosse um dos lugares onde elas exercem, de modo privilegiado, alguns de seus mais temíveis poderes. (FOUCAULT, 2014, p. 09)
}

\footnotetext{
${ }^{7}$ Aqui me refiro ao que se diz como norma (normal), fruto de uma concepção produzida em uma sociedade machista, sexista e cuja fonte se inspira na noção de corpo natural/biológico.
} 
Esta interdição também produz sentido nas matrizes de gênero, impedindo, assim, outras produções de significado que não as binárias. (BUTLER, 2012a) Este binarismo aparece no diagrama produzido por Cordero (2012).

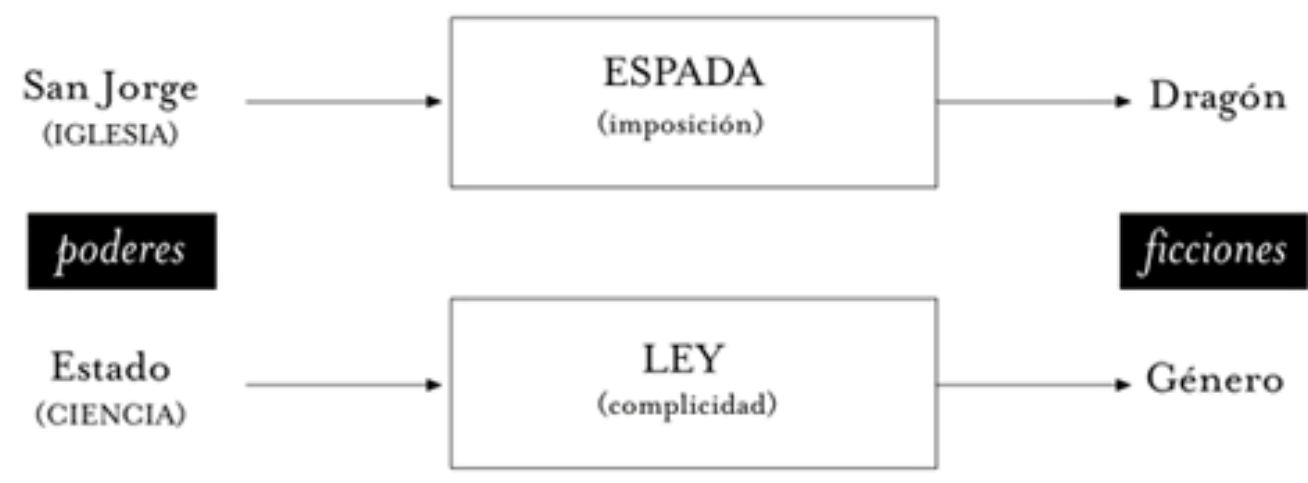

Diagrama analítico da obra.

Fonte: www.oihana.cordero.com

Este diagrama apresentado por Cordero (2012), de certa forma, dialoga com a obra São Jorge e o Dragão de Raphael Sanzio (1506), atualmente exposta na National Gallery of Art em Washington, Estados Unidos da América.

São Jorge e o Dragão (1506) trata de uma das duas versões do tema elaborada pelo artista, que pertencia a uma série de painéis em miniatura que Raphael pintou em Florença para o célebre tribunal de Urbino. A obra retrata um soldado romano de fé cristã. Nela São Jorge salva a filha de um rei pagão subjugando um dragão com sua lança, matando-o. A princesa, em seguida, leva o dragão para a cidade, o que leva o rei e seus súditos a se converterem ao cristianismo. Importa situar historicamente que Raphael nasce em Urbino (1483), um ducado da Itália central. O pintor, conhecido pela sua gentileza e elegância, na adolescência muda-se para Florença no final de 1504, onde lá pinta a obra São Jorge e o Dragão.

Para além dos elementos figurativos (cavalo, dragão, soldado e lança/espada), a obra de Raphael (1506), assim como a de Cordero (2012), alicerça-se em metáforas binárias. No caso de São Jorge e o Dragão, o bem (cavaleiro) e o mal (dragão). Já em La ley no escrita (2012), Cordero dialoga entre a espada, força impositiva da lei, neste caso o contrato de gênero, e o Estado, que a partir de sua força (poder) produz a norma. Este diagrama, portanto, representa o diálogo que a artista visual produz entre os caracteres ficcional de gênero de sua obra e da produção imagética rafaelita de um dragão. 
Estas leituras de imagens, sejam elas pictóricas ou escultóricas, tem auxiliado a desvelar múltiplas análises no campo das ciências sociais, inclusive nos enredamentos entre arte e direito. De acordo com Dias (2015),

\begin{abstract}
os estudos do campo visual representam, atualmente, uma potente possibilidade que desloca para o centro o olhar sobre a visualidade. De cunho eminente interdisciplinar, os estudos através das imagens rompem com os recortes epistêmicos e com decisões compartimentadas, produzem-se, assim, infinitas combinações e desdobramentos.
\end{abstract}

Neste sentido, defende-se como fundamental para o campo do direito a aproximação com as narrativas artísticas e literárias, estando elas inseridas em espaços expositivos fechados como museus e galerias de arte ou em meios de comunicação de massa. Na contemporaneidade, os estudos culturais e interdisciplinares que envolvem os temas arte e direto podem fomentar leituras e reflexões paradigmáticas.

De um modo bastante peculiar as investigações com imagens nos atravessam e nos contaminam positivamente, escavando leituras sobre nosso cotidiano, nossas experimentações e sentidos. No que tange às obras de arte é possível afirmar que suas narrativas e linguagens visuais se aproximem de efeitos de realidade.

Por outro lado, a leitura das visualidades em diálogo com o campo do saber jurídico pode contribuir epistemologicamente no desdobramento de novas produções discursivas sobre as identidades de gênero e sexualidades.

2. Identidades de gênero: a (in)visibilidade de sujeitos e corpos

Esta obra como objeto conceitual (FREIRE, 2006) produz uma (im)potência expressa para além de um documento legal perfurado, ela objetiva provocar as pessoas a refletir sobre suas práticas e seus corpos, mas, sobretudo, reflexionar como estes perímetros são de difícil transgressão. Uma arte conceitual é a que situa ou incita o observador a refletir sobre o que é e o que não é arte (WANNER, 2010, p. 171).

\footnotetext{
Para procurar descobrir o que é arte, é necessário retornar à experiência dos sentidos para o pensamento, isto é, se voltar para a filosofia. A arte conceitual, portanto, acontece em um espaço onde o objeto arte não está necessariamente presente, e sua apreensão tem que se dar num espaço mental, intelectual. Trata-se, portanto, de
} 
signos que dependem de uma experiência colateral para serem apreendidos. (WANNER, 2010, p.176)

$\mathrm{Na}$ escultura, as folhas atravessadas pela espada se destinam a ser tomadas pelo público, portanto, a obra é interativa. Como possui uma característica de ser intervinda, Cordero (2012) explicitou este sentido. A ideia central é a de que se alguém puxar uma folha para levar consigo, o contrato se rompe. A ruptura/quebra ocorre, assim, física e conceitualmente.

A minha proposta é que as pessoas levem a folha, leiam e pensem sobre o que está expresso naquele pedaço de papel, mas, claro, você pode imaginar o quão é complicado que o público, mesmo estimulado, puxe uma folha. $\mathrm{O}$ problema com esta obra (tipo de obra) é que ela possui uma estética de trabalho conceitual, o que faz com que o público não se atreva a tocá-lo (CORDERO, 2012)

Acredito profundamente que a arte serve para pensar, para apresentar, influenciar e mudar realidades. Neste sentido, entendo que eu elaboro práticas artísticas que expressam um ativismo transfeminista. (CORDERO, 2012)

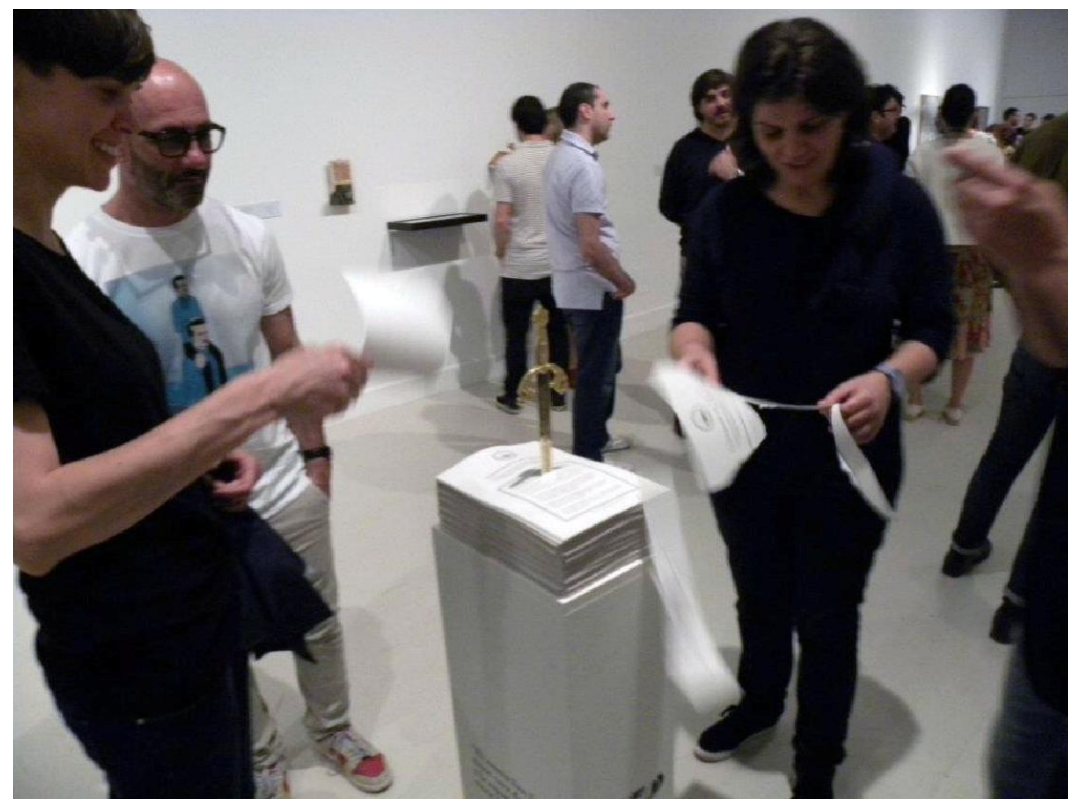

Cena da intervenção dos visitantes à obra. Fonte: www.oihana.cordero.com

No entanto, ao se depararem com a obra, embora explicitado que a mesma está proposta para ser intervinda, muitas pessoas se constrangem com a provocação e não a tocam. Seria esta uma questão da própria obra, que se encontra em um espaço museológico e, portanto, esteticamente intocável, ou seria uma interdição imposta pela construção social de gênero dos sujeitos que a observam? 
Segundo Cordero ${ }^{8}$,

quando você faz um trabalho artístico e coloca em museu, ele tende a se tornar um objeto intocável (literalmente). Para mim, me chamou a atenção uma tarde no CAC Malaga puxando uma das folhas da Ley no escrita, apesar de ter instruções deixadas no trabalho, eu tive que convencer o guarda que a obra estava lá para isto (ser intervinda). Neste sentido, o trabalho tornou-se uma vítima do contexto. Por outro lado, é extremamente difícil escapar à estetização do objeto. Neste sentido, a prática artística é totalmente pré-condicionada pela própria ideia. Assim, o artista individual, em muitas ocasiões, é também uma vítima deste contexto. Sobre propício para a ativação do ambiente de lei não escrita: é complicado porque ele foi criado na armadilha de que falamos e mudar o contexto não é suficiente para a recuperação imediata. De qualquer forma, mesmo havendo esta dificuldade, devo dizer-lhes que é um prazer ver as folhas sendo rasgadas pelas pessoas e, especialmente, ouvir o som. Imagine como soa bem no cubo branco. (CORDERO, 2015)

Para Plaza (2003),

\begin{abstract}
a partir de um conceito de arte como divergência da norma, do código e da convenção na geração de interpretantes (significados), a arte instala um desarranjo nos hábitos, crenças, expectativas e convenções instituídas como significados estabelecidos. (p.44)

O artista-teórico põe em prática um a ação contemplativa, de examinador e especulador sistemático. Com lucidez vai ao encontro dos princípios que fundamentam a sua arte. É neste sentido que ele se opõe a o mistério e à ingenuidade em arte. (p. 46)
\end{abstract}

Neste duplo sentido, desarranjo e contemplação, a obra La ley no escrita nos inquieta a problematizar como o direito e as normas jurídicas (sociais) impõem interdições capazes de regular nossas identidades de gênero. Estas implicações sugerem, para além do fazer/saber artístico, o quão os discursos jurídicos estão perpassados por dogmas e padrões estáticos sobre as questões de gênero e sexualidades.

A norma, e os discursos (FOUCAULT, 2014) que a rodeiam, silencia os corpos. Este silêncio (velado ou explícito) exclui, abjeta, nega a possibilidade de outro sujeito corpóreo. E mais, a partir desta narrativa discursiva excludente, se estigmatizam as identidades divergentes. Enfim, este silêncio produz um por vezes um vazio, produz, inclusive, dor e morte.

Considerações finais ou Interdição de gênero: a lei que silencia o corpo

Ao se analisar a possível intersecção sobre as identidades de gênero e um objeto artístico dentro do campo jurídico espera-se manejar elementos capazes de desvelar as

\footnotetext{
${ }^{8}$ Entrevista com Oihana Cordero. http://curadormag.com/hola-oihana/ <acesso em 10.03.2015>
} 
tecnologias políticas corporais complexas (LAURENTIS, 1989) e assim direcionar luz as multifacetadas matrizes de produção dos sujeitos.

$\mathrm{Na}$ contemporaneidade evidenciam-se regras e regulamentações impostas pelo binarismo de gênero que violentam sujeitos e aprisionam identidades em prol da normalização (normatização) dos corpos.

\begin{abstract}
Nossos corpos constituem-se na referência que ancora, por força, a identidade. E, aparentemente, o corpo é inequívoco, evidente por si; em conseqüência, esperamos que o corpo dite a identidade, sem ambigüidades nem inconstância. Aparentemente se deduz uma identidade de gênero, sexual ou étnica de "marcas" biológicas; o processo é, no entanto, muito mais complexo e essa dedução pode ser (e muitas vezes é)equivocada. Os corpos são significados pela cultura e, continuamente,, por ela alterados. Talvez devêssemos nos perguntar, antes de tudo, como determinada característica passou a ser reconhecida (passou a ser significada) como uma "marca" definidora da identidade; perguntar, também, quais os significados que, nesse momento e nessa cultura, estão sendo atribuídos a tal marca ou a tal aparência. (LOURO, 2000, p. 10)
\end{abstract}

Para Preciado (2011) somente um movimento de oposição (contra hegemônico) poderia resistir a produção disciplinaria de gênero e de sexualidade. É o que Preciado denomina de contrasexualidade.

\footnotetext{
La contrasexualidad es también una teoría del cuerpo que se sitúa fuera de las oposiciones hombre/mujer, masculino/femenino, heterosexualidad/homosexualidad. Define la sexualidad como tecnología, y considera que los diferentes elementos del sistema sexo/género denominados «hombre», «mujer», «homosexual», «heterosexual», «transexual», así como sus prácticas e identidades sexuales, no son sino máquinas, productos, instrumentos, aparatos, trucos, prótesis, redes, aplicaciones, programas, conexiones, flujos de energía y de información, interrupciones e interruptores, llaves, leyes de circulación, fronteras, constreñimientos, diseños, lógicas, equipos, formatos, accidentes, detritos, mecanismos, usos, desvíos... (PRECIADO, 2011, p. 13)
}

Ao que produz a norma, seja ela jurídica ou social, importa desconstruir este paradigma dominante e sexista dual, que joga para a periferia e marginaliza o corpo dito estranho (LOURO, 2000). Entende-se que o processo de estranhamento faz parte da construção de uma sociedade que dialoga a partir das diferenças, e nelas reconheça as multiplicidades identitárias, sejam de gênero, sexo, etnia, raça ou qualquer outro matiz.

A voz e o discurso são mecanismos de comunicação e de linguagem do corpo. O silêncio sua interdição. É preciso produzir novas estratégias que rompam com a reprodução social excludente (BOURDIEU, 2011). Estas rupturas podem ser problematizadas tendo como ponto de partida inúmeros elementos e métodos. Nesta investigação utilizou-se uma delas, a produção artística visual. 
Defende-se o entrelaçamento epistêmico entre arte e direito como um potente diálogo compreensivo entre campos do conhecimento, especialmente a partir dos estudos culturais. Acredita-se que este diálogo pode aprofundar os debates sobre identidade de gênero, ainda tão carecedores de problematização na área jurídica. Num outro sentido, em uma sociedade que se diz plural e democrática, os estudos pós-identitários tornam-se fundamentais, seja para fazer emergir outras leituras de mundo ou para (re)significar desejos, corpos e identidades.

Referências bibliográficas

AUGÉ, Marc; DIDI-HUBERMAN, Georges; ECO, Umberto, L'expérience des images. Paris, France: INA, 2011.

AUMONT, Jacques. A imagem. 9. ed. Campinas, São Paulo: Papirus, 2004.

BARTHES, Roland. A Câmara clara. Lisboa, Portugal: Edições 70, 2012.

BOURDIEU, Pierre. Las estratégias de la reproducción social. Buenos Aires, Siglo Veintiuno Editores, 2011. . La domination masculine. Paris: Éditions du Seuil, 1998.

BUTLER, Judith. El Género em disputa. El feminismo y La subversión de La identidad. Barcelona. España. Paidós, 2013.

Deshacer el Género. Barcelona. España. Paidós, 2012a.

. Cuerpos que importan. Sobre los limites materiales y discursivos del "sexo". Bs As. Argentina. Paidós, 2012b.

CANCLINI, Néstor Garcia. Culturas híbridas: estratégias para entrar e sair da modernidade. 4. ed. São Paulo: Editora da Universidade de São Paulo, 2003.

DIAS, Renato Duro . Acesso à justiça e educação jurídica: uma percepção imagética do direito. In: CONPEDI/UFSC. (Org.). Direito, Educação, Ensino e Metodologias Jurídicos. 1ed. Florianópolis: CONPEDI 2014, 2014, v. 01, p. 29-43.

Séries de animação: diálogos entre direito, arte e cultura popular. In: CONPEDI/UFS.

(Org.). Direito, Arte e Literatura. Florianópolis: CONPEDI, 2015 (no prelo).

DIAS, Renato Duro. As uniões homoafetivas: um estudo sobre as formas de (re)pensar os direitos dos homossexuais. In: Gênero, Educação, Sexualidade e Conhecimento. 1ed. Pelotas: Editora da UFPel, 2011.

FRASER, Nancy. Da redistribuição ao reconhecimento? Dilemas da justiça numa era "póssocialista". Cadernos de Campo, São Paulo, 2006. 
A Justiça Social na globalização: redistribuição, reconhecimento e participação. Revista Crítica de Estudos Sociais, outubro, 2002.

Paulo, 2009.

Reenquadrando a justiça em um mundo globalizado. Lua Nova, n.77, São

FREIRE, Cristina. Arte Conceitual. Rio de Janeiro: Jorge Zahar, 2006.

FOUCAULT, Michel. História da sexualidade. V. 1, 2 e 3. Rio de Janeiro: Graal, 1997-98.

FOUCAULT, Michel. As palavras e as coisas: uma arqueologia das ciências humanas. São Paulo: Martins Fontes, 2000.

. A verdade e as formas jurídicas. Rio de Janeiro: Nau Editora, 2005.

A ordem do discurso. 24 ed. São Paulo: Edições Loyola, 2014.

HARAWAY, Donna. Manifiesto para Cyborgs. Ciencia, Tecnología Y Feminismo Socialista a finales del siglo XX. Mar Del Plata, Argentina. Puenteaéreo Editores, 2014.

JOLY, Martine. Introdução à análise da imagem. Campinas, SP: Papirus, 2003.

A imagem e os signos. Lisboa, Portugal: Edições 70, 2005.

KRAUS, Rosalind. A escultura no campo ampliado. In: Revista Gávea, n.1, revista do Curso de Especialização em História da Arte e Arquitetura no Brasil, da PUC-Rio, em 1984, p. 8793.

LAMAS, Marta. Cuerpo: diferencia sexual y gênero. Ciudad de México, México: Taurus, 2002.

(Comp.). El género: la construcción cultural de la diferencia sexual. Ciudad de México, México: PUEG UNAM, 2013.

LAURENTIS, Teresa de. Technologies of Gender. Essays on Theory, Film and Fiction, London, Macmillan Press, 1989.

LOURO, Guacira Lopes (Org.). O corpo educado: pedagogias da sexualidade. Belo Horizonte: Autêntica, 2000.

PANOFSKY, Erwin. Iconografia e iconologia: uma introdução ao estudo da arte da Renascença. In: Significado nas Artes Visuais. Tradução: Maria Clara F. Kneese e J. Guinsburg. São Paulo: Perspectiva, 2a ed., 1986, p. 47-65.

PLAZA, Júlio. Arte/ciêcia: uma consciência. ARS (São Paulo), vol.1, no.1, São Paulo, 2003.

PORTUGAL, Daniel B.; ROCHA, Rose de Melo. Como Caçar (e ser caçado por) imagens: entrevista com W. J. T. Mitchell. Revista da Associação Nacional dos Programas de PósGraduação em Comunicação |E-compós, Brasília, v.12, n.1, jan./abr. 2009. 
PRECIADO, Beatriz. Manifiesto contrasexual. Barcelona: Editorial Anagrama, 2011.

SCOTT, Joan Wallach. Género e historia. México: FCE, 2008.

SERÉN, Maria do Carmo. Metáforas do sentir fotográfico. Porto, Portugal: CPF, 2002.

WANNER, Maria Celeste de Almeida. Paisagens sígnicas: uma reflexão sobre as artes visuais contemporâneas. Salvador: EDUFBA, 2010.

WELLER, Wivian; BASSALO, Lucelia de M. B.. Imagens: documentos de visões de mundo. Sociologias, vol.13, n. 28. Porto Alegre, Sept./Dec. 2011. 